\title{
BIOLOGIC RESPONSES TO LOW LEVEL LEAD EXPOSURE
}

\author{
KENZABURO TSUCHIYA, KEN TAKAHASHI, HARUHIKO SAKURAI, \\ YUKIO SEKI and MINORU SUGITA
}

\author{
School of Medicine, Keio University, Tokyo, Japan
}

(Received for publication August 13, 1976)

\begin{abstract}
The purpose of this study was to examine the dose-response relationship in low level lead exposures. Four groups of workers were exposed to four different levels of lead in ambient air. The first group composed of industrial lead workers were exposed to about $7 \mu \mathrm{g} / \mathrm{m}^{3}, 6 \mathrm{hrs}$ per day, 6 days per week, in an electric wire producing factory. A second group consisting of policemen was exposed to lower lead levels of about $0.5 \mu \mathrm{g} / \mathrm{m}^{3}$. A third group of rubber hose workers was exposed to the highest lead level of $33 \mu \mathrm{g} / \mathrm{m}^{3}$ during working hours, and the fourth group (control) consisted of white collar workers from the same electric wire factory as the first group. In these four groups, ALA level in urine, which is believed to indicate the earliest undesirable biologic effect due to lead, revealed about the same values in all four groups. Only one parameter, blood lead level, was significantly different among the groups. Blood lead level in the rubber hose workers revealed $32 \mu \mathrm{g} / 100 \mathrm{ml}$. The other three groups showed from 15 to $17 \mu \mathrm{g} / 100 \mathrm{ml}$. The lowered hemoglobin level in electric wire workers was found to be related to the educational level of the workers but not to lead in blood, since the control workers showed higher hemoglobin values. Thus it was concluded that the lead level in ambient air which results in recognizable increase of blood lead might exist between 3 to $6 \mu \mathrm{g} / \mathrm{m}^{3}$.
\end{abstract}

NOTE: This paper was presented at the XVIIth International Congress on Occupational Health in Buenos Aires in September 1972 and references which have appeared since that time have not been included.

\section{INTRODUCTION}

The specific biologic responses to high concentrations of lead have been well documented, but those to low level lead exposures are not fully understood, particularly in terms of dose-response relationship. This study was performed to examine whether or not industrial lead exposure to about $7 \mu \mathrm{g} / \mathrm{m}^{3}$ (mode value), 
6 hours a day, 6 days a week, in lead-covered electric wire cable production would cause any specific biologic responses due to lead absorption. In addition, some data were added from policemen who had been exposed to low level lead in the ambient air, as well as some data from industrial workers who had been exposed to lead of a slightly higher concentration, in order to compare the results with those from the electric wire workers. It was noted that the electric wire workers showed statistically lower mean values of hemoglobin and specific gravity of blood in comparison with control employees of the same company. These differences are not believed to have been caused by lead exposure. Some efforts have been made in order to explore the reason why the electric wire workers revealed slightly lower average hemoglobin values than the control group.

\section{MATERIALS AND METHODS}

Eighty-one workers and 26 white collar employees from an electric wire plant were subjected to this study. Lead in the air of the working environment was measured several times a day over a period of one month by a low volume sampler with membrane filter as well as by personal samplers. Each subject was interviewed by the investigators, inquiring for age, educational and occupational history, annual income, smoking and drinking habits, and medical history. As for laboratory tests, specific gravity of blood, ALA, hemoglobin, hematocrit, basophilic red cells, lead in blood and urine were checked. Lead in urine, however, was not determined because of contamination which occurred during transportation. Some data from other studies on policemen and rubber hose workers were used in the evaluation of the study of electric wire workers. In the former studies, coproporphyrin and lead in urine were determined in addition to the other laboratory tests mentioned above. Lead in the air was calibrated by atomic absorption spectrophotometry after collection. Lead in blood and urine was determined by the dithizone mixed-color method. ALA in urine was measured by the Granick and Mauzerall method, ${ }^{1}$ and coproporphyrin by the Askevold method modified by With.2

\section{RESULTS}

Lead concentrations in the air of the working environment of the electric wire plant fluctuated from 0 up to $100 \mu \mathrm{g} / \mathrm{m}^{3}$ with an average about $10 \mu \mathrm{g} / \mathrm{m}^{3}$. However, the mode value of lead concentrations appeared to be lower than $10 \mu \mathrm{g} / \mathrm{m}^{3}$. As shown in Table 1 , the mean value of the actual lead exposure measured by personal samplers was $12.8 \mu \mathrm{g} / \mathrm{m}^{3}$, and the mode value was estimated to 
Table 1

Actual Exposure to Lead - By Personal Sampler--

\begin{tabular}{|c|c|c|}
\hline Name & Work Hour (min) & $\mathrm{Pb} \mu \mathrm{g} / \mathrm{m}^{3}$ \\
\hline 1. & 353 & 5.3 \\
\hline 2. & 351 & 4.9 \\
\hline 3. & 351 & 15.4 \\
\hline 4. & 347 & 9.5 \\
\hline 5. & 356 & 25.4 \\
\hline 6. & 357 & 3.5 \\
\hline 7. & 347 & 35.4 \\
\hline 8. & 353 & 3.1 \\
\hline Mean & 352 & 12.8 \\
\hline
\end{tabular}

Table 2

Summary Data

\begin{tabular}{|c|c|c|c|c|c|}
\hline \multirow{2}{*}{ Item } & \multicolumn{2}{|c|}{ Exposed Workers } & \multicolumn{2}{|c|}{ Control } & \multirow{2}{*}{$\begin{array}{c}\text { Test of } \\
\text { Significance }\end{array}$} \\
\hline & Mean & S. D. & Mean & S. D. & \\
\hline Age & 35.7 & 11.2 & 34.1 & 10.2 & \\
\hline GB & 1.0559 & 0.0023 & 1.0575 & 0.0020 & * \\
\hline Baso. & 0.284 & 0.427 & 0.178 & 0.196 & \\
\hline Lead in Blood & 15.4 & 8.4 & 17.7 & 11.1 & \\
\hline Protein in Urine & 33.7 & 9.7 & 37.0 & 12.2 & \\
\hline$\triangle \mathrm{ALA}$ & 1.51 & 0.87 & 1.54 & 0.78 & \\
\hline $\mathrm{Hb}$ & 14.1 & 0.9 & 14.6 & 0.8 & * \\
\hline $\mathrm{Ht}$ & 45.5 & 2.9 & 46.8 & 2.0 & \\
\hline Corrected Blood Pb & 15.4 & 8.7 & 17.1 & 11.2 & \\
\hline Educational level & 8.7 & 1.3 & 12.5 & 3.5 & ** \\
\hline
\end{tabular}

Remarks: * $\mathrm{P} \leqq 0.05$

** $\mathrm{P} \leqq 0.01$

be about $7 \mu \mathrm{g} / \mathrm{m}^{3}$. As the working place of workers was rotated every day, it was assumed that all the workers were exposed to lead of about $7 \mu \mathrm{g} / \mathrm{m}^{3}$ on the average, 6 hours a day, 6 days a week. A summary of the blood and urine test results are shown in Table 2 . As shown in the table, there were no significant differences between the exposed workers and the white collar control group in the results of tests performed or answers to the questions asked, except for specific gravity of blood, hemoglobin, and educational level. Figure 1 shows the distri- 


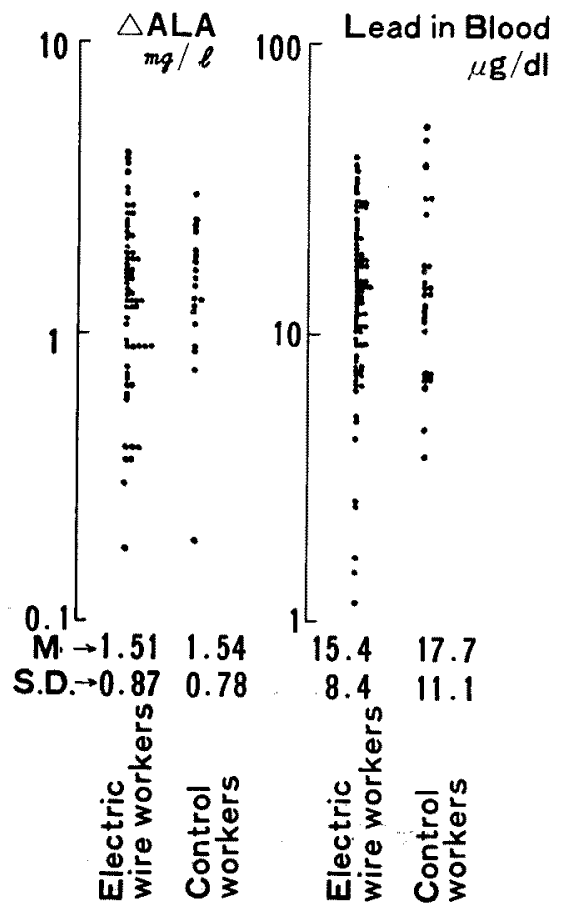

Fig. 1 Lead in Blood Coproporphyrin and ALA

- Electric Wire Workers and Control Workers -

butions of ALA values in urine and those of lead concentration in blood, which resulted in the same means and standard deviations for both the exposed and control groups. Figure 2 shows a scatter diagram indicating the association between specific gravity of blood and educational level. The association was statistically significant with a correlation coefficient of 0.364. As the age factor was also associated with specific gravity of blood and hemoglobin, as shown in Figure 3, the partial correlations between educational level and levels of hemoglobin, specific gravity of blood and hematocrit were calculated, fixing the age factor. The results are shown in Figure 4. Significant partial correlations between educational level and specific gravity of blood as well as between educational level and hemoglobin were noted.

In Table 3, ALA, coproporphyrin, lead in urine, and lead in blood were compared among policemen, lead workers in the electric wire plant, white collar employees of the same company, and rubber hose workers. Lead exposures of these four groups were derived from lead determinations in the ambient air 


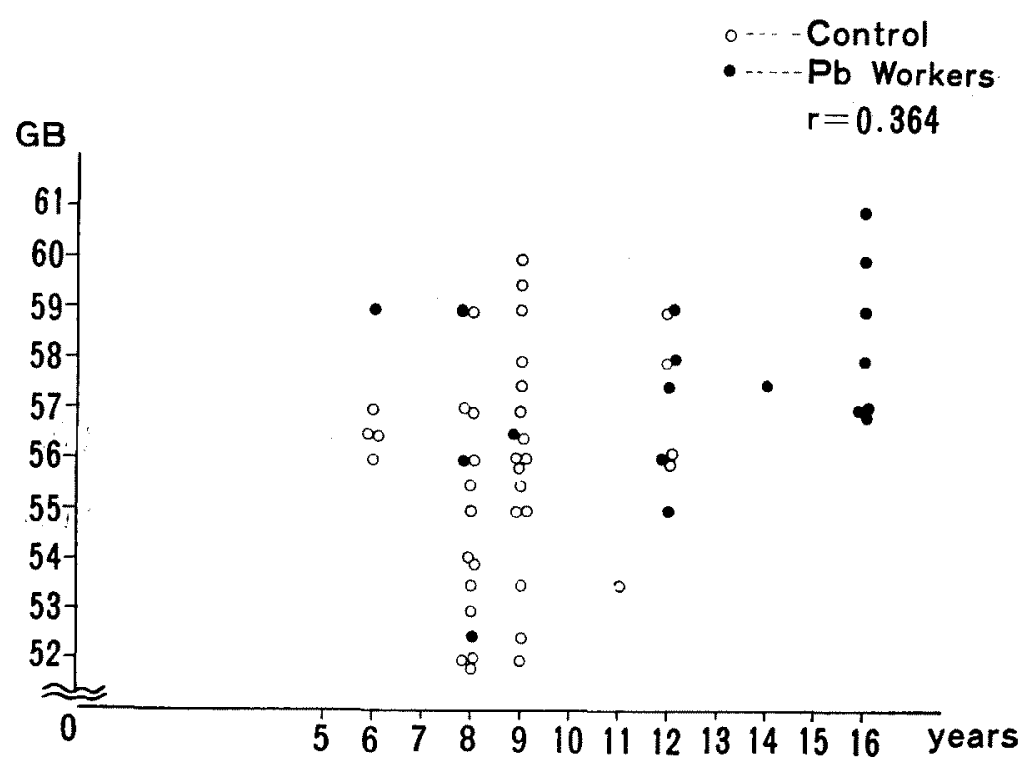

Fig. 2 Blood Gravity and Educational Level.

Table 3

Comparison of Biologic Responses due to Various Lead Exposure

\begin{tabular}{c|c|c|c|c}
\hline & \multirow{2}{*}{ Policemen } & \multicolumn{2}{|c|}{$\begin{array}{c}\text { Electric Wire Plant } \\
\text { Workers }\end{array}$} & $\begin{array}{c}\text { Rubber Hose } \\
\text { Workers }\end{array}$ \\
\cline { 2 - 5 } & & Lead & Control & \\
\cline { 2 - 5 } $\mathrm{N}$ & 100 & 81 & 26 & 43 \\
\hline$\triangle$ ALA $(m g / \ell)$ & 2.3 & 1.5 & 1.5 & 2.0 \\
Copro $(\mu \mathrm{g} / \ell)$ & 36 & - & - & 64 \\
Pb in urine $(\mu \mathrm{g} / \ell)$ & 17 & - & 17 & 38 \\
Pb in blood $(\mu \mathrm{g} / 100 \mathrm{~g})$ & 17 & 15 & $0.5 \sim 1.0$ & $10^{*} \mu \mathrm{g} / \mathrm{m}^{3}$ \\
\hline Estimated Total Lead & $0.5 \sim 1.0$ & $2.0 \sim 3.0$ & 0 & 32 \\
\hline Exposure $\left(\mu \mathrm{g} / \mathrm{m}^{3} / \mathrm{day}\right)$ & & & & \\
\hline
\end{tabular}

* Occupational Exposure: $33 \mu \mathrm{g} / \mathrm{m}^{3} 7$ hours a day 6 days a Week. 


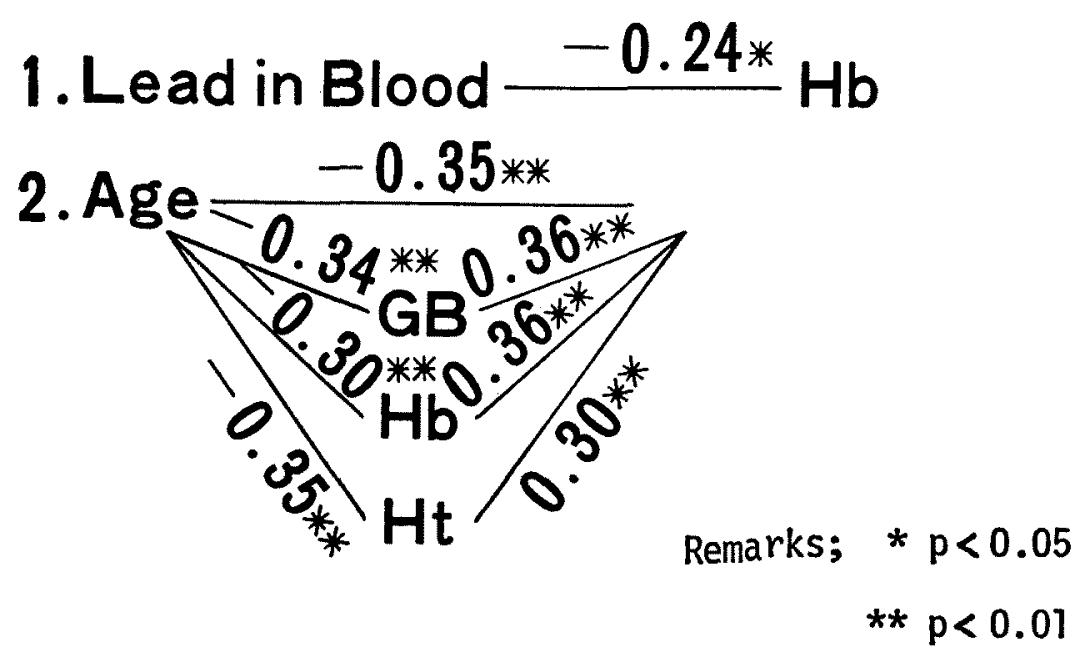

Fig. 3 Correlations between variables.

- Including control -

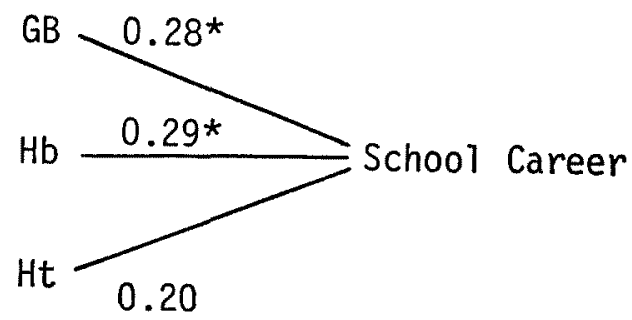

Remark; $* p<0.05$

Fig. 4 Partial Correlations between $\mathrm{Hb}, \mathrm{GB}, \mathrm{Ht}$ and Educational level (Age-fixed).

throughout the year 1971 in Kanagawa Prefecture, where most of the people in question were living and working, and from air lead determinations of the working environment, using low volume as well as personal samplers. The overall average lead exposures per day throughout the year were determined as shown in the table. Lead in urine and blood showed higher values in rubber hose workers than in the other three groups. Lead in blood was $15-17 \mu \mathrm{g} / 100 \mathrm{~g}$ on the average in the latter three groups, whereas it was $32 \mu \mathrm{g} / 100 \mathrm{~g}$ in the rubber hose workers who were estimated to be exposed to lead of roughly $10 \mu \mathrm{g} / \mathrm{m}^{3}$ daily throughout the year based on the fact that lead in their working environment showed $33 \mu \mathrm{g} / \mathrm{m}^{3}$ per day. However, ALA was not significantly elevated in the rubber hose workers, although the coproporphyrin level showed a slightly hightly higher average in those workers. Since the dates of examination differed 
for each group, the difference in the coproporphyrin data may be due to technical or unknown factors.

\section{DISCUSSION}

Recently, many researchers have shown interest in health effects of lead exposure at low levels, as lead in the ambient air has been increasing over the past several decades. Some years ago, Kehoe ${ }^{3}$ performed human experiments in connection with dose-response relationship. More recently, a large scale field study was performed by a group from the University of Cincinnati (Seven City Lead Study).4 According to these studies, it is believed that the lead exposures from the ambient air up to about $3.4 \mu \mathrm{g} / \mathrm{m}^{3}$ throughout the year do not cause increase of the lead concentration in blood. However, another study ${ }^{5}$ estimated a gradual increase of blood lead corresponding with the increase of air lead up to $5 \mu \mathrm{g} / \mathrm{m}^{3}$, extrapolating data from a number of studies. The results of the present study support those of the "Seven City Lead Study."

Electric wire workers who had been exposed to an average lead level of $7 \mu \mathrm{g} / \mathrm{m}^{3}, 6$ hours a day, 6 days a week, during working hours and to 0.5 to 1.0 $\mu \mathrm{g} /{ }^{3}$ at home did not show any changes of ALA in urine or increased blood lead. However, the workers showed slightly lower mean hemoglobin and specific gravity of blood. Lowered hemoglobin level was found not to be associated with lead absorption but to be clearly related to the educational level of the workers, which may be reflected in general living conditions.

The rubber hose workers who had been exposed to an average lead level of $33 \mu \mathrm{g} / \mathrm{m}^{3} 7$ hours a day, 6 days a week, showed elevated blood lead concentrations without increase of ALA in urine. It was assumed that this was equivalent to an exposure of $10 \mu \mathrm{g} / \mathrm{m}^{3}$ in terms of a daily average throughout the year. A separate study is required in order to determine what level of lead in the air causes biochemical changes such as the increase of ALA in urine. A paper on this subject was presented at the XVIIth ICOH in Buenos Aires, September $17-23,1972 .^{6}$

\section{CONCLUSION}

Lead-exposed and control workers in an electric wire plant engaged in lead coating were examined to determine whether or not the exposed workers indicated health effects from low level lead exposure of about $7 \mu \mathrm{g} / \mathrm{m}^{3}$ in the air of their working environment. The data from a study on policemen whose exposure to lead is lower than that of the electric wire workers and a study on rubber hose 
workers who had been exposed to higher levels of lead (higher than both electric wire workers and policemen) were used in order to evaluate the whole spectrum. The following conclusions were drawn.

1. The electric wire workers did not show any type of health effect, including the increase of blood lead and ALA in urine due to lead.

2. These same workers revealed slightly lowered hemoglobin levels, which was not associated with lead absorption but assumed to be related to general living conditions.

3. There were no differences in ALA leaves in urine and blood lead concentrations among policemen, electric wire workers, and control workers.

4. The rubber hose workers who had been exposed to lead levels of $33 \mu \mathrm{g} / \mathrm{m}^{3}$ in their working environment showed an elevated mean blood lead concentration with no increase of ALA level in urine. Although these workers showed slightly elevated coproporphyrin in urine, other unknown factors, including technical factors, are believed to be involved.

\section{REFERENCES}

1. Granik, S. and Mauzerall, D.: The occurrence and determination of detaaminolevulinic acid and porphobilinogen in urine. J. Biol. Chem. 219: 435, 1956

2. With, T. K. and Agerlin Petersen, H. C.: Symptomatic Uroporphyrinuria. Lancet 268: 1148,1954

3. Kehoe, A. A.: Experimental studies on the inhalation of lead by human subjects. Pure Appl. Chem. 3: 129, 1961

4. Tepper, L. B.: Seven city study of air population of environmental health. College of Medicine, University of Cincinnati, 11 pp., 1971

5. Goldsmith, J. R. and Hexter, A. C.: Respiratory exposure to lead; Epidemiological and experimental dose-response relationships. Science 158: 132, 1967

6. Tsuchiya, K., Seki, Y. and Sugita, M.: Biological criteria for exposures to lead and cadmium. Presented at the International Congress on Occupational Health in Buenos Aires, September 17-23, 1972. (Keio J. Med. 25: 91, 1976) 